\title{
EL DERECHO CONSTITUCIONAL EN SU CONTEXTO: EL ÁMBITO CULTURAL DEL CONSTITUCIONALISMO ${ }^{1}$
}

\author{
CARLOS ORTEGA SANTIAGO \\ Profesor de Derecho Constitucional \\ Universidad de Valladolid
}

\author{
SUMARIO \\ I. Introducción. \\ II. Los orígenes del constitucionalismo y su \\ desarrollo en el siglo XIX \\ III. El constitucionalismo del siglo Xx. Los re- \\ tos del Derecho constitucional en el siglo \\ XXI
}

\section{INTRODUCCIÓN.}

El Derecho Constitucional se caracteriza por unos rasgos definidores que lo distinguen de otras ramas del saber jurídico ya que se trata, propiamente, del momento más radical del Derecho, el de su creación y fundamento. Es el Derecho que funda la comunidad política, a través del que se expresan las decisiones trascendentales de una sociedad, el que determina en gran medida el modo y las condiciones de vida de los individuos que se integran en un proyecto común de convivencia. Aquí el Derecho se enfrenta a la ordenación y a la solución de los problemas de más calado que afectan al hombre en su dimen-

1 El presente Texto (presentado como comunicación a las Jornadas sobre Orientación y Método del Derecho Constitucional organizadas por la revista Teoría y Realidad Constitucional el 16 de noviembre de 2007) es un extracto del Proyecto Docente presentado a las habilitaciones para Profesor Titular de Derecho Constitucional convocadas en los últimos años. Para este artículo se ha preferido aligerar en lo posible las referencias bibliográficas, con el objeto de reducir la extensión del texto y facilitar su lectura. Es preciso señalar que, aunque no se explicite en las presentes páginas, para la elaboración del Proyecto Docente en general, y de esta parte en concreto, han sido un referente esencial los Proyectos Docentes de los profesores A. Fernández-Miranda Campoamor, P. Biglino Campos y F. CaAmaño Domínguez. 
sión social: El alcance de su libertad, sus derechos frente al poder, la participación en la vida pública y en la orientación política del Estado.

Esta especificidad del Derecho Constitucional y de su objeto principal de estudio, la Constitución, sitúan a esta disciplina jurídica en un contexto y en unas coordenadas únicas que singularizan a esta forma de organizar el poder de otras que se han dado en la historia: el complejo movimiento cultural que denominamos constitucionalismo, enclavado en un tiempo (la modernidad) y en un espacio (el mundo occidental) determinados. Ciertamente, el Derecho Constitucional es un Derecho del Estado, en el sentido de que organiza el poder político, constituye al mismo; y, desde este punto de vista, no puede ser explicado si no es a partir de esa forma jurídica de organizar el poder, la última en el tiempo, que es la forma estatal. De ahí se deriva, precisamente, una íntima vinculación entre el movimiento constitucional y el proceso de secularización del poder impulsado por la reforma protestante y por la renovación cultural y espiritual del Renacimiento, las cuales contribuyeron de manera decisiva a la formación del Estado moderno que se vio reforzado, desde el punto de vista teórico, a partir de las aportaciones de Bodino, Hobbes y Maquiavelo.

Del mismo modo, no puede negarse que el ideal de Constitución no surge espontáneamente en los procesos revolucionarios de los siglos XVII, XVIII y XIX, sino que se sustenta sobre siglos de pensamiento filosófico y de larga evolución de las teorías políticas ${ }^{2}$. Sin embargo, para el constitucionalismo no basta con la existencia de una forma política que se organiza a partir de la igualdad de sus integrantes, como ocurre con el Estado, a diferencia de lo que ocurría con las formas políticas de la antigüedad, según queda claramente explicitado, por ejemplo, en Aristóteles, cuando habla del lugar propio de los esclavos en la polis. Y tampoco es suficiente para ese movimiento cultural con que el poder se discipline a través de una serie de reglas, doctrinas y prácticas, porque eso puede predicarse de cualquier forma de organización política, incluidas aquéllas basadas en el origen divino de un poder que es, por esta razón, absoluto, como queda claramente explicitado por Bodino en los Seis Libros de la República, cuando se refiere a las leyes divina y natural, y a las justas convenciones y tratados en que participan, como leyes a las que están sometidos los príncipes.

El constitucionalismo se organiza a partir del Estado, pero añade algo más, ya que se caracteriza por aglutinar a los individuos no sólo en torno a la idea de igualdad, sino también a la idea de libertad frente al abuso y la tiranía. La Constitución del constitucionalismo es, sí, una forma de regular el poder y su actuación, pero a partir de determinadas ideas que no pueden encontrarse

2 En palabras de M. FioravanTI, “... La Constitución de los antiguos es también un gran proyecto de disciplina social y política de las aspiraciones de todas las fuerzas agentes: de los monarcas, para que no se conviertan en tiranos; pero también de la aristocracia, para que no se transforme en oligarquía cerrada; y también del pueblo, para que no oiga la voz de los demagogos. Los antiguos, entonces, dejan en herencia a los tiempos sucesivos esta gran idea: que una comunidad política tiene una forma ordenada y duradera, en concreto una Constitución...", en Constitución, de la antigüedad a nuestros dias, Trotta, Madrid, 1999, págs. 30 y ss. 
más que esbozadas en la antigüedad: La de la igualdad de los ciudadanos, la del poder temporal y limitado, la del triunfo de los derechos de los individuos como fundamento y justificación de la comunidad política.

Para lograr establecer una organización del poder estatal con estas características se requiere un elemento imprescindible de partida, el reconocimiento de que el ejercicio del poder exige el consentimiento de los gobernados. Consentimiento que se expresa (que se presupone) en el momento de creación de la comunidad, a través del pacto social, que se materializa en el contrato constitucional $^{3}$. Consentimiento que es necesario, a su vez, en el gobierno ya constituido, de modo que los gobernantes han de ser nombrados por elección y, además, a través de elecciones periódicas, para que los ciudadanos puedan exigir responsabilidades y renovar o, en su caso, revocar, la confianza depositada en los representantes que los gobiernan.

Esta necesidad de las elecciones periódicas como garantía de un gobierno libre, responsable y legitimado en la confianza de los ciudadanos es esencial en los orígenes del constitucionalismo $o^{4}$. De cualquier forma, para que el consentimiento de los gobernados sea pleno, la participación en el proceso representativo ha de ser democrática, abierta a todos los ciudadanos; presupuesto que, a diferencia de lo planteado a nivel teórico con el consenso constituyente, no fue la regla en los orígenes del Estado constitucional en cuanto a la elección de los gobernantes 5 .

Desde este punto de vista, el poder constituyente por un lado, y el gobierno representativo (democrático) por otro, son dos de las mayores novedades del constitucionalismo propio de la época moderna, y se incardinan en el paradigma del gobierno constitucional como un gobierno limitado, a través de los instrumentos de la separación de poderes y del reconocimiento de los derechos de los ciudadanos. Evidentemente, esta construcción del poder es fruto del

3 Para T. PAINE, «Una Constitución es algo que antecede a un gobierno y un gobierno no es más que la criatura de una Constitución. La Constitución de un país no es el acto de un gobierno, sino del pueblo que constituye su gobierno. Es el cuerpo de elementos al que cabe remitirse y citar artículo por artículo y que contiene los principios en los que ha de establecerse el gobierno, la forma en que se organice éste, los poderes que tendrá, la forma de las elecciones, la duración del Parlamento [...] y, en fin, todo lo relacionado con la organización completa de un gobierno civil y los principios en los que se basará y por los que se regirán, en Derechos del hombre: respuesta al ataque realizado por el Sr. Burke contra la Revolución francesa, trad. de F. Santos Pontela, Alianza Editorial, Madrid, 1984, pág. 69.

4 Así, por ejemplo, en A. Hamilton, J. Madison, J. Jay, El Federalista, Cartas LII y LIII, FCE, México, 1998, págs. 223 y ss.

5 Eso es lo que lleva a T. PAINE a afirmar que "... Sería discutible si cualquier hombre o clase de hombres tiene el derecho de excluirse a sí mismo, pero, sea como fuere, no puede tener el derecho de excluir a otro... La desigualdad de derechos se crea por maniobra de una parte de la comunidad para privar a la otra de sus derechos. Cada vez que se hace un artículo de una Constitución o de una ley en la que el derecho de votar o elegir y ser elegido pertenezca exclusivamente a las personas que poseen cierta cantidad de propiedad, sea mucha o poca, es una maquinación de las personas que poseen aquella cantidad para excluir a quienes no poseen la misma. En investirse a sí mismos con poderes como una parte autocreada de la sociedad, con la exclusión del resto", en El sentido común y otros escritos, Tecnos, Madrid, 1990, pág. 36. 
pensamiento racional y supone una conquista histórica que avanza lentamente, sigue ritmos diferentes y goza de caracteres singulares en los diversos países donde se produce. No obstante, la mayoría de los autores aglutina esa diversidad en torno a tres impulsos o movimientos constitucionales: el británico, el estadounidense y el continental-europeo; movimientos en los que, por otra parte, ya se encuentran explicitados, o subsisten in fieri, los elementos esenciales que han determinado y siguen determinando esa forma de organizar el poder que es el Derecho Constitucional ${ }^{6}$.

\section{LOS ORÍGENES DEL CONSTITUCIONALISMO Y SU DESARROLLO EN EL SIGLO XIX}

\section{A) El MOVimiEnto CONSTituCiOnAl BRITÁNico.}

El proceso revolucionario británico trajo como resultado final la consolidación de un régimen político basado en una Constitución no escrita, consuetudinaria, y en el monopolio de la soberanía por parte de un órgano constituido, el Parlamento, que no está sujeto a límites en su actuación; dos extremos que, de partida, encajan mal con un principio esencial en el movimiento constitucional: La organización del poder a través de una Constitución escrita obra de un poder constituyente que se distingue de los poderes constituidos, cuyas actuaciones no pueden ser contrarias al pacto de consenso que es la Constitución. La Constitución consuetudinaria británica no surge de un movimiento voluntarista de la humanidad iluminada que pretende a través de la razón crear un orden político nuevo que rompe con el pasado. En este aspecto se centra, precisamente, la crítica de E. Burke a la Revolución francesa y el elogio de la continuidad de las instituciones inglesas?

6 Según N. MatTEucci, el constitucionalismo moderno, el movimiento constitucionalista, “... muestra su máxima creatividad en el plano de las ideas y de las soluciones prácticas con la Revolución americana y con la francesa; después en los siglos XIX y XX tendremos solamente una imitación de los grandes modelos (inglés, francés, americano) o simples variaciones en temas que tienen ya su gramática bien consolidada", en Organización del poder y libertad, Trotta, Madrid, 1998, pág. 24.

7 Aunque, después de dos siglos largos de historia la realidad parecería desposeer de razón al pensador inglés y a la "vía constitucional británica", cuando en tiempos recientes se ha incorporado al sistema constitucional del Reino Unido una Declaración de derechos (la Human Rights Act) que vincula, con muchas peculiaridades, al legislador; cuando se discute en ese país la elaboración de una Constitución escrita; o cuando se somete a las leyes del Parlamento (aunque sea el escocés) a un control judicial (en la Scotland $A c t$ ). Ya A. V. DiceY apuntaba en esta dirección a finales del s. XIX, cuando afirmaba que "[El profesor de Derecho constitucional] debe sentir también, a pesar de lo atractivos que puedan ser los misterios de la Constitución, que tiene buenas razones para envidiar a los profesores que pertenecen a países como Francia, Bélgica o los Estados Unidos, ocupados con cuestiones cuyos términos deben encontrarse en documentos escritos, conocidos y accesibles para cualquier persona capaz de leer. Cualesquiera que sean las ventajas de la llamada Constitución "no escrita", su existencia impone especiales dificultades a los docentes sujetos a exponer sus pre- 
En cualquier caso, las peculiaridades del constitucionalismo británico no han sido impedimento para que el proceso revolucionario que dio lugar a la instauración del primer régimen constitucional, y para que el propio régimen constitucional, contengan in nuce o en desarrollo algunos de los principios esenciales del Estado constitucional. En primer término, no se puede olvidar que es durante el período revolucionario británico del siglo XvII cuando aparecen los primeros textos constitucionales de la historia moderna: El Agreement of the free english people de $1649 \mathrm{y}$ el Instrument of Government de 1653. Se trata, en ambos casos, de constituciones escritas que, pese a no estar en vigor (el Agreement de los niveladores), o estarlo por poco tiempo (el Instrument de O. Cromwell), están dotados del contenido y de los caracteres propios de las constituciones tal y como se entienden en el constitucionalismo continental y americano.

Se configuran como límite del poder político que se encargan de organizar y como norma fundamental y suprema que vincula a aquél. Y ambos reconocen a su vez, aunque sea de manera rudimentaria, derechos subjetivos que el poder (legislativo) no puede vulnerar. Más aún, el Agreement atribuye los poderes esenciales al Parlamento como representante de la nación, e instaura un gobierno representativo basado en la igualdad de los ciudadanos, en las elecciones anuales y en el sufragio democrático. Se trata de un proyecto constitucional que supone, en cierto sentido, una ruptura con la tradición, ya que pretende legitimarse en su intrínseca racionalidad, como ocurrirá después, precisamente, con la Constitución americana de 1787, con la Declaración de los Derechos del Hombre de 1789, y con la Constitución francesa de $1791^{8}$.

En otro sentido, también en Inglaterra se sitúan determinados antecedentes políticos y teóricos íntimamente vinculados al concepto de Constitución propio del constitucionalismo: La institución del control de constitucionalidad de las leyes por el poder judicial y la teoría del doble pacto social como fundamento de la sociedad. El juez Coke y John Locke como precedentes de las aportaciones de la revolución americana. El primero, asentando las bases de la independencia judicial frente al ejecutivo, que después tomará cuerpo en el Act of Settlement (1701); y situando a los jueces y tribunales como guardianes del common law (en el Bonham's case de 1610), del derecho constitucional consuetudinario que el Parlamento no puede vulnerar.

El segundo, afirmando que el pacto social que saca al hombre del estado de naturaleza es un acuerdo para formar una única comunidad política cuyo fin

visiones", Introduction to the Study of the Law of the Constitution, Mac Millan, Londres, 1897 (se cita por la $10^{a}$ edición de 1959 , pág. 4).

8 Como apunta M. Revelui, Putney. Alle radici della democracia moderna, Boldini e Castoldi, Milán, 1997, pág. 201, «Entre los protagonistas principales de los debates de Putney figura, sin duda, la igualdad. O mejor, las distintas acepciones que el concepto de igualdad ha asumido en la modernidad. Bien visto, en las encendidas discusiones que se desarrollaron entre las severas maderas del coro que acogió aquella extraordinaria asamblea de representantes del Nuevo Modelo, el repertorio completo de las igualdades — la igualdad $<<$ jurídica $>>$, la política y la social- encuentra encarnación y voz en las distintas figuras que discuten y se enfrentan...". 
es garantizar los derechos individuales del hombre; a diferencia del pacto hobbesiano, cuyo único objeto es garantizar la seguridad y la supervivencia de los individuos imposible en el estado de naturaleza. Aunque no se explicite, en J. Locke está presente la distinción entre pactum subiectionis y pactum associationis, que es la razón de ser del Estado constitucional y de la distinción entre poder constituyente y poderes constituidos?.

Es de sobra conocida la influencia de J. Locke en el proceso constituyente americano, en la concepción que tienen las colonias independientes de su nueva comunidad política, creada para buscar la felicidad, para garantizar la tríada sagrada de los derechos a la vida, a la libertad y a la propiedad. En definitiva, en el pensador inglés podemos encontrar algunos presupuestos aún hoy vigentes que pueden ser de utilidad para distinguir propiamente un Estado constitucional de un Estado donde existe un texto escrito al que se llama constitución pero que no puede ser propiamente un Estado constitucional cuando se basa en un presupuesto incompatible con el constitucionalismo: La posibilidad de que los individuos renuncien a su libertad y a su dignidad a través del pacto social.

Después diremos algo sobre esta cuestión y sobre los nuevos retos del constitucionalismo en culturas hostiles a la fórmula liberal-democrática, como pudiera ser el Islam. Ahora sólo añadiremos respecto de Locke y sus aportaciones en el marco de la revolución británica una cosa más. La concepción lockiana del pacto social lleva a considerar que el poder legislativo, aunque sea el poder supremo de la comunidad, es siempre un poder limitado, sujeto a la Constitución (a los derechos de los ciudadanos). Sin embargo, la garantía de esa sujeción no se sitúa para este autor en el ámbito de la jurisdicción, sino en el ámbito de la política: El pueblo tiene derecho a instaurar un nuevo poder legislativo si éste actúa contra sus derechos. Se trata de un remedo del derecho de resistencia o del derecho a la revolución, pero no para instaurar un orden nuevo sino para preservar la tradición.

Este planteamiento sobre las garantías políticas de la Constitución no ha dejado de estar presente en el pensamiento constitucional y, en buena medida, sigue teniendo proyección en nuestros días. Por ejemplo, ese es el sentido que se ha dado en nuestra doctrina al referéndum popular previsto en nuestra Constitución para ratificar las reformas constitucionales, siempre que el contenido de las mismas vulnere los límites implícitos que le serían propios ${ }^{10}$. Y esta idea discurría también sobre el Proyecto de Constitución para Europa y se puede adivinar en la Declaración del Tribunal Constitucional 1/2004, de 13 de

9 En el pensamiento político de J. Locke «El poder despótico... deriva de un acto de fuerza y se basa sólo en la fuerza, no en el consenso o en la ley. Bajo el gobierno despótico continúa existiendo un estado de naturaleza (o de guerra) entre el príncipe absoluto y los súbditos...", N. MATTEUCCi, op. cit., pág. 134.

10 Así P. DE Vega García, “Sólo cuando... el referéndum constitucional se plantea como el instrumento político de control, comienzan a esclarecerse las dudas y a disiparse muchos de los interrogantes que en torno al mismo han sido erróneamente suscitados", La reforma constitucional y la problemática del poder constituyente, Tecnos, Madrid, 1988, pág. 114. 
diciembre, cuando parece considerarse que la garantía de la supremacía de la Constitución frente a la primacía del Derecho Comunitario no es ya tanto de carácter jurisdiccional, confiada al Alto Tribunal, sino más bien de carácter político, concretada en el derecho que asiste en último extremo a los Estados para retirarse voluntariamente de la Unión (artículo I-60) ${ }^{11}$.

Una última cuestión en torno a las aportaciones de la revolución británica, relacionada con la forma de gobierno parlamentaria y la compatibilidad entre monarquía y principio democrático. A día de hoy, la soberanía popular exige que la monarquía parlamentaria se sitúe en unas coordenadas que ya están predeterminadas en la Gloriosa revolución. Una esencial, que la legitimidad de la Corona se funda no en la tradición histórica ni en la herencia dinástica, sino en la voluntad popular, expresada en Gran Bretaña a través del Act of Recognition (1690) y del Act of Settlement (1701); y, en la actualidad, necesariamente en la Constitución.

En cuanto a la posición que es propia en nuestros días del Jefe del ejecutivo, tanto en las formas de gobierno presidenciales como en las parlamentarias, la experiencia británica, a través de convenciones que han dado lugar con el paso del tiempo al gobierno de premierato, ha sido y sigue siendo un precedente fundamental. Aparte de los referentes clásicos de la exigencia de responsabilidades a los miembros del gobierno por parte del Parlamento (Impeachment), de la facultad de disolver las Cámaras del Primer Ministro, o de la legitimación electoral (indirecta) del mismo a través del sistema de partidos y de ostentar la mayoría en la Cámara, hay otras cuestiones menos explícitas, pero no por ello menos importantes, cargadas de actualidad. Así ocurre con la progresiva asunción por parte del Primer Ministro de la prerrogativa del Rey, convirtiéndose en el auténtico King in Parliament que, gracias a su control sobre la mayoría parlamentaria, mantiene una serie de atribuciones sobre las que el Parlamento no entra a legislar; por ejemplo, cuestiones tan trascendentales como la negociación de los tratados, la declaración de la guerra o la prerrogativa de gracia.

Esa asunción de las funciones propias del monarca por el jefe de gobierno en las monarquías democráticas, y la relegación del monarca del ámbito de las competencias decisorias, conduce, en último extremo, a una aproximación cada vez mayor entre las formas de gobierno parlamentarias y presidenciales. Así se manifiesta, por ejemplo, de modo claro, en la atribución para declarar y hacer la guerra: La formulación británica en la que esa decisión es prerrogati-

11 «En el caso difícilmente concebible de que en la ulterior dinámica del Derecho de la Unión Europea llegase a resultar inconciliable este Derecho con la Constitución española, ..., en última instancia la conservación de la soberanía del pueblo español y de la supremacía de la Constitución que éste se ha dado podrían llevar a este Tribunal a abordar los problemas que en tal caso se suscitaran, ..., ello aparte de que la salvaguarda de la referida soberanía siempre resulta a la postre asegurada por el art. I-60 del Tratado, verdadero contrapunto de su art. I-6, y que permite definir en su real dimensión la primacía proclamada en este último, incapaz de sobreponerse al ejercicio de una renuncia, que queda reservada a la voluntad soberana, suprema, de los Estados miembros", DTC 1/2004, f.j. $4^{\circ}$ in fine. 
va del Rey (Primer Ministro) sigue en vigor en nuestros días (con reciente praxis parlamentaria -intervención en Irak - en sentido diferente y propuestas de reforma legal); y se traslada como problema al constitucionalismo escrito americano (con reflejo en el constitucionalismo actual de ese país, pero también en el nuestro), por la confluencia en ese ámbito del poder presidencial como Jefe Supremo de las Fuerzas Armadas y del poder del Congreso para declarar la guerra ${ }^{12}$.

\section{B) El MOVImiento CONSTITUCiOnAL NORTEAMERICANO.}

El segundo gran impulso del constitucionalismo se produce con la revolución americana, donde se aprueban las primeras constituciones escritas (la federal y las de algunos estados) que han permanecido vigentes hasta nuestros días. La extensión y la naturaleza de este artículo hacen imposible dedicarse ampliamente a los orígenes del constitucionalismo americano, donde confluyen una multiplicidad de referentes ideológicos, filosóficos y religiosos que permiten explicar la fuerza con la que arraigó en las colonias inglesas el concepto de Constitución, ya tuviera como referente el covenant religioso, la chartre real, o el compact $t^{13}$.

En línea de principio, se puede decir que en el constitucionalismo americano se va a afirmar un concepto diverso de Constitución peculiar respecto del francés, a pesar de la forma escrita que se impone para los textos constitucionales en ambos procesos revolucionarios. La singularidad americana sobre la que interesa insistir es que la Constitución no pretende imponer un orden inmutable, basado en la razón, fijo e invariable, como se planteó en Francia, donde la Constitución llega a entenderse como la imposición de la ley de la naturaleza en las relaciones sociales ${ }^{14}$.

12 Esta semejanza de las formas de gobierno parlamentaria y presidencial, y los problemas de articulación entre poderes, estaban ya presentes en el constitucionalismo del s. XIX, como se pone de manifiesto, por ejemplo, en W. BAGEHOT, para el que "La principal función de la Cámara de los Comunes es una que conocemos bien, aunque nuestro lenguaje constitucional común no la reconoce. La Cámara de los Comunes es una cámara electoral; es la asamblea que elige a nuestro Presidente", The English Constitution, 1867.

13 Como señala F. Rey Martínez, “... la Constitución federal de 1787 no surge en el vacío, sino que se enmarca en un proceso de raíces profundas [...] es imposible comprender la Constitución federal en un espléndido aislamiento, sin tener en cuenta simultáneamente las Constituciones de los Estados... En otras palabras, la tradición constitucional americana es muy anterior a la Constitución federal de 1787, e incluso a la Declaración de 1776. La búsqueda de los orígenes de esta tradición nos conduce a las Constituciones de los Estados, a los documentos coloniales de fundación (charters) y a los textos anteriores sobre los que se basaban, los pactos políticos escritos por los colonos ingleses en Norteamérica (compacts)...", "La ética protestante y el espíritu del constitucionalismo", en La democracia constitucional, CD-CEPC, Madrid, 2002, págs. 6 y 7.

14 Hasta el extremo de que "En la Constituyente francesa hubo quien pensaba que la reforma constitucional no solamente no debía ser admitida sino incluso prohibida con amenaza de muerte [...] En este punto, los dos conceptos de revolución (o de poder constituyente, en el sentido revolucionario) y de Constitución —el segundo hijo del primero- devienen irreductiblemente enemi- 
La Constitución americana es fruto de la necesidad y es instrumento práctico para organizar ex novo un poder estatal recién nacido. Evidentemente, la idea iusnaturalista del poder constituyente que impone límites a los poderes constituidos está presente en la Constitución americana, en la rigidez de la misma, pero no en su irreformabilidad, porque esto último sería en la práctica una imposición de los muertos sobre los vivos, una limitación para que las generaciones vivas se organicen del modo que consideren más conveniente, para mejorar el pacto y adaptarlo a las necesidades de los tiempos.

En este aspecto, las cláusulas de reforma agravada juegan una doble función: Permiten adaptar la Constitución a la realidad de cada momento histórico, a la vez que perpetúan el pacto fundador de la comunidad como mito que se ha de preservar. Esta concepción que se impone en la Constitución americana, y que encuentra su máximo defensor en J. Adams, tiene como telón de fondo una concepción de la Constitución similar a un pacto entre generaciones (al modo postulado en la actualidad por P. Häberle), en contraposición con una visión de las generaciones en una sucesión independiente que permite a cada una de ellas empezar de cero, crear su propia Constitución y no someterse a las leyes de las generaciones pasadas. Así se encuentra explicitado, por ejemplo, en T. Jefferson o en algunos textos constitucionales del período de la Convención en Francia. Por lo demás, esta perspectiva tiene gran trascendencia para definir los momentos históricos que demandan reformas de la Constitución, los límites de las mismas y los consensos preservadores del mito fundacional que son necesarios para sacarlas adelante.

Decíamos antes que la Constitución americana nace como instrumento práctico, como solución técnica, para regular una nueva realidad, y ese es precisamente el espíritu que impregna a esa glosa política de dicha Constitución que es El Federalista ${ }^{15}$. Esta instrumentalidad de la Constitución se demuestra en la construcción de un gobierno equilibrado donde la figura del Presidente se ofrece como la mejor solución posible para los excesos previsibles del legislativo (ya verificados con antelación en algunas de las asambleas de las colonias), y donde se organiza el poder como el equilibrio de una maquinaría, a través de frenos y contrapesos.

Y lo mismo ocurre con el Senado y con su causa directa, la organización federal. El reparto de competencias y la relación entre ordenamientos tienen unos antecedentes evidentes en el propio sistema británico de relación con las colonias, pero los americanos adaptan esos precedentes a la articulación de un reparto territorial del poder prácticamente inédito en el Estado moderno, que sigue definido por “... una de las características que más lo diferencia de los Es-

gos. O sobrevive la revolución, y con esto la Constitución es contradicha; o bien sobrevive la Constitución, y entonces la revolución se termina, es decir, el orden constitucional es establecido à jamais, G. Zagrebelsky, Historia y Constitución, Trotta, Madrid, 2005, pág. 39.

15 Donde nos encontramos con «... un razonamiento fundado exclusivamente sobre el <<buen sentido>>, y por tanto sobre el cálculo político, que parte siempre de los hechos, de un frío y lúcido examen de la situación, de un realismo que no concede nada a divagaciones utópicas", $\mathrm{N}$. Matteucci, op. cit., pág. 210. 
tados federales que surgirán más adelante en Europa. Desde su aparición hasta la actualidad, los Estados Unidos han funcionado al margen del principio de competencia, tal y como se entiende en nuestros sistemas jurídicos ${ }^{16}$.

La Constitución como pacto, pero también la Constitución como solución técnica, habían de conducir, tarde o temprano, a la Constitución como instrumento para resolver conflictos o, de otra forma, a la aplicabilidad de la Constitución, a la afirmación de su naturaleza normativa. La aprobación de las Enmiendas constitucionales del 1791 con el Bill of Rights americano evidenció aún más la necesidad de limitar la omnipotencia del Parlamento y controlar su actuación. Y a ello se unió la necesidad de resolver los conflictos que podían derivarse de la coexistencia de varios centros de poder en el seno de la Federación. La conclusión, el reforzamiento del poder judicial como garante e intérprete de la Constitución; su instrumento, el judicial review incorporado por el juez Marshall en un razonamiento perenne en la historia del constitucionalismo:

"... los poderes del legislativo están definidos y limitados; y, con el fin de que estos límites no puedan ser malinterpretados u olvidados, la Constitución es escrita. Es expreso cometido y deber del poder judicial decir cuál es la ley... Si una ley está en desacuerdo con la Constitución, el tribunal debe determinar cuál de estas dos reglas en desacuerdo se aplica al caso... De esta manera... la Constitución de los Estados Unidos confirma y refuerza el principio, que se supone esencial a todas las constituciones escritas, de que una ley contraria a la Constitución es nula, y que los tribunales, como las otras ramas del gobierno, están vinculados por este instrumento", Sentencia del caso Marbury vs. Madison, 1803.

Supremacía normativa de la Constitución, judicial review y reforma agravada son los principios que sustenta el constitucionalismo americano casi en solitario durante todo el siglo XIX, hasta que irrumpen en Europa, transformados, con el constitucionalismo democrático de entreguerras. Y han seguido influenciando el constitucionalismo europeo hasta nuestros días, a través de formas eclécticas donde la jurisdicción constitucional ya no es únicamente concentrada sino también difusa, y no sólo abstracta sino también incidental. En este sentido, la garantía del ordenamiento jurídico comunitario encomendada a los tribunales ordinarios de los Estados miembros está produciendo una $m u$ tación trascendental en el ámbito del control judicial de las leyes nacionales, con supuestos de intervención judicial inaplicadora de normas con rango legal proscritos en los sistemas de jurisdicción constitucional concentrada pero que, en función del principio de primacía, han encontrado una ventana de entrada en los sistemas constitucionales europeos, incluido el español, a través de la función de preservación del ordenamiento comunitario, con los problemas que eso genera ${ }^{17}$.

16 P. Biglino Campos, "En los orígenes del federalismo: La formación del modelo norteamericano", en La democracia constitucional, cit., Vol. II, pág. 1131.

17 Como se ha puesto de manifiesto, por ejemplo, en la STC 58/2004, de 19 de abril. 
Un último apunte respecto del constitucionalismo americano y de la Sentencia Marbury vs. Madison. En esta decisión podemos encontrar dos dimensiones más de la Constitución dignas de relevancia hasta nuestros días, aunque no sean principales en la Sentencia. Una, el problema de los actos políticos y la posibilidad de que determinadas actuaciones del poder estén exentas de control jurisdiccional para preservar un adecuado equilibrio de poderes y evitar la "aristocracia de la magistratura". Otra, íntimamente ligada a la anterior, la pertinencia de que el Alto Tribunal del país se coloque en una posición de self-restraint respecto de las controversias que puedan llegar a su conocimiento, ya que las respuestas del Derecho (constitucional) a los conflictos que surjan en el ámbito de lo público no se han de encontrar siempre y en todo momento en los órganos jurisdiccionales (un buen ejemplo a este respecto pueden ser los Autos del Tribunal Constitucional español 135/2004, de 20 de abril, sobre el llamado "Plan Ibarretxe" y 85/2006, de 15 de marzo, sobre la propuesta de reforma del Estatuto de Autonomía de Cataluña).

\section{C) El MOVIMiENTO CONSTITUCIONAL FRANCÉS.}

El proceso revolucionario francés es un gran laboratorio donde están presentes muchos de los planteamientos políticos que van a determinar la historia constitucional europea hasta nuestros días. Sin embargo, el hecho de que sea en la Declaración de Derechos del Hombre y del Ciudadano de 1789 donde aparezca explicitado el contenido ineludible y definidor de las constituciones del constitucionalismo ("Toda sociedad que no asegura la garantía de los derechos, ni determina la separación de poderes, no tiene Constitución"), no tuvo continuación en el mundo de la realidad política.

Ni en Francia ni en Europa se asienta un modelo constitucional al estilo del americano, estable, consensuado en el seno de la sociedad. En el continente, como reflejo de la experiencia francesa, los distintos países ven sucederse las constituciones como resultado del equilibrio de fuerzas existente en cada momento histórico. La tesis de la revolución y la antítesis de la restauración, la preeminencia de la ideología liberal o la prevalencia del tradicionalismo, convierten a Europa en el escenario de la inestabilidad constitucional. De esta forma la Constitución escrita, en vez de convertirse en el instrumento de fundación de la comunidad política a través de una decisión irrevocable que rompe con el antiguo régimen, deviene en un concurso abierto por ver quien escribirá una mejor, como apuntaba el tradicionalista J. de Maistre.

Por esta razón, puede decirse que el constitucionalismo francés y continental es el de las tareas pendientes para el Derecho constitucional. La articulación técnica y no coyuntural de la división de poderes, la solución del problema monárquico, las garantías de la Constitución, la preeminencia del Parlamento como órgano representativo de los ciudadanos, o la vinculación del legislador a los derechos de éstos, quedan diferidos durante todo el siglo XIX. Curiosamente, en la Europa continental se logra codificar y dotar de certeza a 
las relaciones privadas, pero no a las relaciones de poder. El triunfo de la monarquía constitucional conlleva el triunfo de las constituciones sin soberanía, las constituciones flexibles donde los titulares del poder constituyente (Rey y Parlamento) son los mismos que los ejercientes de los poderes constituidos. El equilibrio decimonónico de poderes nacido del pacto entre la aristocracia y la burguesía, entre el monarca y la asamblea representativa, es una respuesta de situación que obligará al Derecho constitucional europeo a un esfuerzo innovador considerable cuando el principio democrático se incorpore a los textos constitucionales ${ }^{18}$.

Sólo en el período de entreguerras, como se dirá después, se alcanzan a consolidar sistemas que hacen compatible la forma republicana con el parlamentarismo, al estilo de la monarquía parlamentaria (tras el fracaso de la II República presidencial con el Imperio de Napoleón III); y el parlamentarismo con la estabilidad gubernamental, a través de las distintas fórmulas del parlamentarismo racionalizado.

La suerte de los derechos de los ciudadanos como límite a la actuación de los poderes públicos, incluido el legislativo, también es peculiar en el constitucionalismo continental, y ello tendrá repercusiones, a su vez, en el desarrollo del Derecho constitucional europeo. En efecto, en este ámbito el poder constituyente, asociado con la revolución y la inestabilidad permanente, ha de ser domesticado y adaptado a la permanencia de las instituciones políticas. Esta necesidad, nacida de los excesos de la revolución, explica porqué los teóricos más importantes de la teoría constitucional de la época (con Sieyès a la cabeza) puedan confluir con, o mejor, ser redefinidos por, el historicismo tradicional y alumbrar, pasado un tiempo, la doctrina estatalista liberal del Derecho y de los derechos y libertades (Laband, Jellinek, Carré de Malberg, Orlando).

Desde esta perspectiva, el nuevo orden político tiene como centro al Parlamento, órgano del Estado que representa a la Nación y que, por ello, expresa la voluntad general en la forma de la ley. Es la ley, en consecuencia, la mejor garantía de las libertades de los ciudadanos, el legislador es el legitimado para interpretar las declaraciones de derechos contenidas en las constituciones, y ninguna otra interpretación puede prevalecer sobre la que haga el Estado de las mismas. Los derechos no están, pues, en la Constitución, sino en el Estado $^{19}$.

18 Esa realidad es la que sintetiza C. De CABO MaRTín: «La representación, las Asambleas parlamentarias fueron así, el gran invento burgués: permitieron afirmar frente al absolutismo el principio de la soberanía del pueblo y sirvieron a la vez de protección frente a las posibles consecuencias de ese principio en cuanto constituyeron el filtro a través del cual el pueblo real quedaba fuera", en "Algunos aspectos de la problemática "representación-partidos políticos", en Teoría y práctica de los partidos políticos, P. De Vega (ed.), Cuadernos para el Diálogo, Madrid, 1977, págs. 45 y 46.

19 ،[...] la tutela de los derechos garantizados por la Constitución se sustituye por la certeza del derecho garantizado por el Código y por la ley, por el derecho positivo del Estado... en la Europa continental es el Estado de derecho, la ley del Estado, el poder público como reflejo orgánico de la nación, el que custodia los derechos, y por ello es defendido, desde un punto de vista rigurosamente liberal, de las intromisiones desestabilizadoras de la Constitución, del poder constitu- 
Evidentemente, de ahí a la configuración de los derechos de los ciudadanos como derechos públicos subjetivos (Jellinek) hay solamente un paso; y conocidas son las limitaciones que pueden derivarse para la eficacia de los derechos de su necesaria configuración previa por el legislador. Por último, a un Derecho público (no plenamente constitucional) basado en el Estado de Derecho, en la primacía de la ley y en la legalidad de los derechos, el constitucionalismo continental añade también una determinada visión del Estado, como Estado-Nación, que va a justificar la solución centralista europea y que va a ser fuente de tensiones estructurales y territoriales intensas en los Estados plurales del viejo continente, que no van a encontrar solución hasta las constituciones del siglo xx.

Aquí también la reacción "revolucionaria" (Constitución francesa de 1795, Consulado, Napoleón) frente a los peligros de la revolución, va a unirse al tradicionalismo historicista para alumbrar un concepto de Nación radicalmente diferente del que se manejaba en los primeros momentos de la Revolución francesa, como sinónimo de poder constituyente, de pueblo (aunque los jacobinos preferían esta última denominación). A través de esta forzada evolución, el término nación pasará a designar una realidad histórico-natural que no decide de manera voluntarista y por medio de un pacto (constituyente), sino que define sus instituciones políticas a través de la tradición histórica. La culminación de ese proceso de definición de la nación es, claro está, el Estado ${ }^{20}$.

La importancia de esta concepción de la nación y de la soberanía que es su atributo fundamental, impide que se maneje en Europa un concepto menos trascendente de la "puissance" estatal y hace muy difícil en el continente, al menos hasta la renovación conceptual del Derecho constitucional europeo que se afianza tras la II Guerra Mundial, concebir la existencia no sólo de un poder legislativo limitado y sometido a un poder superior (lo cual se logra en el período de entreguerras con la justicia constitucional y con las constituciones normativas), sino además que ese poder legislativo se encuentre repartido y distribuido entre varias instancias territoriales de poder.

\section{EL CONSTITUCIONALISMO DEL SIGLO XX. LOS RETOS DEL DERECHO CONSTITUCIONAL EN EL SIGLO XXI.}

El constitucionalismo liberal define los arquetipos que dan forma al Derecho constitucional occidental como un modo especifico de organizar el poder. En los tres procesos revolucionarios descritos se determina la Constitución como pacto social que pretende constituir a la comunidad política y que actúa

yente, de las voluntades particulares de los individuos y de las fuerzas sociales", M. Fioravanti, Los derechos fundamentales. Apuntes de historia de las constituciones, Trotta, Madrid, 1996, pág. 107.

20 Y todo ello "Conduce, en el terreno de la $<<$ práctica constitucional $>>$, al tránsito de la soberanía nacional a la soberanía parlamentaria", R. BlANCO VALDÉs, El valor de la Constitución, Alianza, Madrid, 1994, pág. 225. 
como límite del poder estatal. Además, la Constitución ha de organizarse a través de la división de poderes y el equilibrio entre los mismos; mientras que todo el edificio constitucional tiene como justificación el reconocimiento y la garantía de los derechos de los ciudadanos. Estos principios, con unos u otros matices, se comunizan en el occidente constitucional y, con unas u otras derivaciones, se afianzan progresivamente a lo largo del siglo XIX.

Pero el paso del tiempo también puso de manifiesto la insuficiencia de estas aportaciones constitucionales para determinar organizaciones estatales integradoras de las pluralidades propias de cada comunidad. El constitucionalismo hubo de enfrentarse, finalmente, con las patologías que fue generando la propia modernidad ("el sueño de la razón produce monstruos"); llegó el momento en que el Derecho constitucional debía mostrar su versatilidad intrínseca (fruto de su "lógica natural") para solucionar nuevos retos.

En un primer momento, el de la reformulación del principio representativo para acabar con el sufragio censitario, incorporar en el circuito de la representación a la clase social (el proletariado) y al sexo (el femenino) mayoritarios, y alargar el consenso constitucional más allá de la burguesía para lograr la propia subsistencia del sistema. En algunos países, los de mayor tradición constitucional, las reformas fueron suficientes para afianzar una verdadera democracia frente a las alternativas que postulaban, a su vez, la supuesta democracia auténtica en una concepción sesgada de la misma: el bolchevismo y el fascismo. Sin embargo, estos últimos movimientos se impusieron, con los resultados catastróficos conocidos, en otros países de escasamente afianzada tradición constitucional (España, Alemania, Italia, el oriente europeo).

La renovación democrática del período de entreguerras trajo como consecuencia la incorporación a las constituciones de instituciones de democracia directa o participativa y supuso, a su vez, la configuración de la forma de gobierno parlamentaria no ya a partir del equilibrio tradicional entre legislativo y ejecutivo propia del siglo xIx, sino a través de "La racionalización del régimen parlamentario [como] tendencia común, [que] se explica por las concepciones políticas de los autores de las nuevas constituciones, y sobre todo por la colaboración de juristas-teóricos que se esfuerzan lo más posible por introducir todo el complejo proceso de la vida política en el marco del Derecho...para proteger a los nuevos Estados contra un parlamentarismo demasiado encrespado ${ }^{21}$.

De manera simultánea a la reformulación del poder a partir del principio democrático, y puede decirse, además, que como consecuencia de ello, se incorpora a Europa el concepto de Constitución normativa, con las implicaciones que eso conlleva desde la perspectiva de la rigidez constitucional y de los procedimientos agravados de reforma de la Norma fundamental, y también desde la dimensión del control de constitucionalidad de las leyes. En este punto, el Derecho constitucional europeo sigue mostrando sus especificidades respecto del

21 B. Mirkine-GuetzeVITH, «Le problème de la rationalisation du pouvoir dans les Constitutions de l'Europe d'après-guerre", en Revue du Droit Public, 1928, págs. 22 y ss. 
americano, pero el constitucionalismo de entreguerras supone un paso fundamental en la aproximación de las soluciones constitucionales en uno y otro Derecho, después del distanciamiento que se produjo a lo largo del siglo XIX.

En este período se incorporan a las constituciones europeas sistemas de jurisdicción constitucional concentrada, como la gran aportación del constitucionalismo continental al sistema de las garantías constitucionales (la Verfassungsgerichtsbarkeit kelseniana), basada en la creación de un órgano jurisdiccional especializado que ostenta el monopolio del control de constitucionalidad de las leyes, a requerimiento de una serie restringida de sujetos legitimados, y que actúa como legislador negativo con la facultad de invalidar las leyes inconstitucionales ${ }^{22}$.

Otra característica fundamental del constitucionalismo democrático de entreguerras que afecta, también, a la posición y a las funciones de la jurisdicción, es la reformulación de la organización territorial del poder a través de un modelo europeo específico que, aunque se llame federal, difiere de la solución americana $^{23}$. La necesidad de preservar este diseño lógico del reparto territorial del poder dotado, desde un punto de vista constitucional, de protección jurídica, explica la competencia propia de los tribunales constitucionales como tribunales de conflictos (lo que se pone de manifiesto en la staatsgerichtsbarkeit weimariana). Por lo demás, es evidente la trascendencia que esta configuración de la jurisdicción constitucional tuvo y sigue teniendo en el constitucionalismo posterior a la II Guerra Mundial.

Por último, el período de entreguerras redefine el Derecho constitucional desde la dimensión esencial de los derechos de los ciudadanos, a través del reconocimiento constitucional de los derechos sociales, económicos y culturales. Aquí la innovación constitucional europea parece poder llegar más lejos que la innovación legislativa americana, donde la Constitución, interpretada por una jurisprudencia conservadora del Tribunal Supremo, se pone como límite a los desarrollos intervencionistas en materia económica y social promovidos por el New deal.

22 Según H. Kelsen, “Un Tribunal que tiene el poder de anular leyes es, por consiguiente, un órgano con Poder Legislativo [...] la institución de la justicia constitucional no está en absoluto en contradicción con el principio de la separación de poderes sino que constituye, por el contrario, una afirmación del mismo... Su independencia, tanto frente al Parlamento como frente al Gobierno, es un postulado evidente. Porque son precisamente el Parlamento y el Gobierno, en su calidad de órganos que participan en el procedimiento legislativo, quienes deben ser controlados por la Justicia constitucional", en ¿Quién debe ser el defensor de la Constitución? (1931), Tecnos, Madrid, 1995, págs. 37 y 38 (en idénticos términos que en "La garantía jurisdiccional de la constitución").

23 Como señala J. Corcuera Atienza, refiriéndose a la Constitución de Weimar, "... la situación previa supondrá la adopción de un modelo sensiblemente diferente, que hace hablar a algunos autores de la existencia de un nuevo "Estado federal sin fundamento federal" [SснмітT] o, lo que es igual, permite pensar en la existencia de un modelo de articulación que ha dejado de ser federal en sentido propio", "El constitucionalismo de entreguerras: La racionalización del poder y sus límites", en Estudios de Derecho Público en Homenaje a Juan José Ruiz-Rico, Vol. I, Tecnos, Madrid, 1997, pág. 73; y lo mismo cabe decir, como también señala este autor, del federalismo austriaco o del Estado integral de la II República española. 
Reformulación de los derechos y reformulación del Estado, comprometido este último constitucionalmente no sólo a través de límites a su actuación, sino también a través de tareas, a través de fines que debe alcanzar. Es el comienzo del Estado social, que se asentará posteriormente de modo estable en la segunda posguerra mundial. Pero las constituciones de este período, las constituciones de los profesores (de los juristas teóricos, según Mirkine-Guetzévith), se mostraron insuficientemente "dúctiles", demasiado positivistas, para poder sustentar una organización del gobierno que canalizase adecuadamente la situación económica, social y política del momento. El conflicto político subyacente en Europa durante el período de entreguerras se convirtió en una confrontación de amigos-enemigos para los que el texto constitucional no servía de referente de compromiso ${ }^{24}$.

Las dictaduras de la época niegan la legalidad como forma exclusiva de la legitimidad (M. Weber); el Estado constitucional democrático, en su positividad, es destruido desde su propia legalidad con el argumento de su carencia de contenido legitimador (su descabalgamiento con la supuesta realidad vital del pueblo). La experiencia traumática que padeció la humanidad como consecuencia directa de esta situación espiritual del período de entreguerras, condujo al penúltimo peldaño en la evolución del constitucionalismo y en la conformación del Derecho constitucional, el espacio en que se enmarca la Constitución española de 1978 y en el que se desarrolla nuestro ordenamiento constitucional.

Lo más relevante es que en este período de la posguerra mundial la Constitución y el Estado, el Estado constitucional, se ponen definitivamente al servicio de la dignidad de la persona y de los derechos que le son connaturales e inalienables. Esta dignidad deviene "la premisa cultural antropológica" de ese Estado (P. Häberle). La primera consecuencia de ese paradigma (la dignidad de la persona como premisa cultural antropológica) es que no puede haber ningún "Derecho sustancial, empapado de moral y justicia" (palabras de C. Schmitt en relación con el derecho emanado por el Führer), si no es en referencia a la dignidad de la persona. Ese es el sentido, precisamente, que cobran en este período las normas sustantivas incorporadas a la parte dogmática de las constituciones, y que se concretan no sólo en derechos y libertades de los individuos, sino también en valores y principios puestos al servicio de su dignidad. Desde un punto de vista práctico, esto ha traído como consecuencia el reforzamiento de los mecanismos de tutela de los derechos fundamentales, tanto jurisdiccionales (amparo) como no (Defensor del Pueblo).

Por lo demás, esta centralidad de los derechos es la que, en la actualidad, ha dotado de plena legitimidad a la legalidad de la Constitución: La "visibili-

24 En las reflexiones de C. SchmitT ya se podía adivinar a qué fin se vería abocado el constitucionalismo democrático de este período: «... Frente a una democracia no sólo técnica, sino también, en un sentido vital, directa, el Parlamento,... parece como una maquinaría artificial, mientras que los métodos dictatoriales y cesaristas no sólo pueden ser mantenidos por la acclamatio del pueblo, sino que, asimismo, pueden ser la expresión directa de la sustancia y la fuerza democrática", en La situación histórico-intelectual del parlamentarismo boy (1923), incluido en la edición Sobre el parlamentarismo, Tecnos, Madrid, 1990, con estudio preliminar de M. ARAGÓN REYES. 
dad" de la Norma fundamental para los ciudadanos, su integración en el proceso público, se ancla de manera básica en el referente de los derechos y libertades reconocidos en la Constitución, como espacio del Derecho donde el individuo y los grupos en que se integra pueden identificarse y sentirse reflejados. $<<$ La Constitución ya no se limita a fijar los límites del poder del Estado frente a la libertad civil, y a organizar la articulación y los límites de la formación política de la voluntad y del ejercicio del dominio, sino que se convierte en la positivización jurídica de los "valores fundamentales" del orden de la vida en común $>25$.

Desde esta dimensión se explica, a su vez, que el Derecho constitucional de nuestros días haya ido construyendo nuevos contextos donde dotar de protección jurisdiccional a los derechos de la persona. No han parecido suficientes las garantías internas, incluso cuando se multiplican las instancias jurisdiccionales donde hacer efectiva esa tutela (tribunales ordinarios, Tribunal Constitucional), o los legitimados para solicitarla (el propio interesado, el Ministerio Fiscal, el Defensor del Pueblo); y se han creado, así, las instancias supranacionales de garantía (específicas como el Tribunal Europeo de Derechos Humanos, o derivadas como el Tribunal de Justicia de las Comunidades Europeas), con las consecuencias que de ello resultan, además, para la relativización del concepto de soberanía en el Estado constitucional europeo actual.

En efecto, ésta puede considerarse la segunda línea directriz del constitucionalismo de nuestros días, ya que el Estado ha dejado de ser el único centro de emanación de decisiones (generales y singulares) vinculantes y eficaces en su territorio, al integrarse en organizaciones supraestatales con capacidad para dictar normas y actos directamente aplicables en el seno del Estado. Además, este fenómeno presenta variaciones de calado respecto del pluralismo normativo ad intra de la organización estatal que se deriva de la distribución territorial interna del poder, ya que implica una situación de pluralismo ordinamental (de convivencia de ordenamientos) que no es inocuo, además, respecto de la pluralidad normativa interna derivada de la descentralización política.

En otras palabras, esta imbricación entre ordenamientos y subordenamientos (integrados a través de la Constitución, J. L. Requejo, Sistemas normativos, Constitución y ordenamiento:La Constitución como norma sobre la aplicación de normas, MacGraw-Hill, Madrid, 1995), entre instancias de poder con capacidad decisoria, exige una constante reformulación de las bases jurídicas en las que se asienta la distribución de competencias entre entes territoriales, si se quiere evitar que los procesos de integración supraestatal y de descentralización intraestatal (habitualmente simultáneos, pero a menudo también paralelos y no convergentes) concluyan en el enmagrecimiento de la capacidad de actuación política autónoma de alguno de esos entes.

Esta atenuación de la propia soberanía del Estado a la que venimos haciendo referencia, con las matizaciones expuestas, puede considerarse una

25 E. W. BöcKENFÖRDE, "Origen y cambio del concepto del Estado de Derecho", ahora en Estudios sobre el Estado de Derecho y la Democracia, Trotta, Madrid, 2000, pág. 40. 
constante que viene apuntada ya en el Estado constitucional liberal y que se confirma en el Estado constitucional democrático, porque en el mismo ya no hay legibus solutus, esto es, un poder situado por encima del Derecho. Evidentemente, el Parlamento y el resto de poderes constituidos actúan sometidos a la Constitución, pero incluso el propio soberano, el pueblo, sólo puede incorporar cambios a la Constitución a través de los procedimientos que ella misma determina. Ni siquiera cabe afirmar, en fin, la "soberanía" de la Constitución, porque ésta es por definición Derecho y no poder ${ }^{26}$.

En este orden de cosas, en la actualidad no cabe entender la Constitución como un edificio ya construido y definido por el poder constituyente, como un espacio absolutamente delimitado que vincula y predetermina la actuación de la comunidad política y de los poderes constituidos o del poder de reforma ${ }^{27}$. Las constituciones actuales son, pues, las constituciones del pluralismo, las constituciones de una integración que precisa de normas "suaves" (mite, dúctiles) que permitan la apertura y la legitimidad de programas políticos diversos susceptibles de convertirse en legislación estatal de acuerdo con los resultados de las elecciones periódicas. Pero no sólo: El Derecho mite ha de permitir también la apertura a otras fuentes de producción normativa capaces de emanar normas eficaces en el seno del Estado, ya sea desde el propio seno de la sociedad civil (convenios colectivos, por ejemplo), ya lo sea desde instancias externas al propio Estado, como se ha dicho antes.

Esa redefinición constitucional asentada en el pluralismo y la integración se articula a partir de un cambio fundamental de las constituciones actuales respecto de los primeros textos constitucionales de la historia. En la Constitución americana de 1787 los constituyentes son "We, the people of the United States", pero ese pueblo está integrado en exclusiva por el hombre blanco, varón y propietario. Ahora, sin embargo, ya no basta ni siquiera con configurar al pueblo a partir del pluralismo intrínseco, esencial, determinante de cada persona (el sexo, la raza, la religión); la homogeneidad de los integrantes de la comunidad política se ha de construir necesariamente a partir de las diversidades extrinse-

26 Y de ahí la importancia que adquiere en la Constitución española el procedimiento de revisión (total) previsto en el art. 168, ya que “... la Constitución supone la positivización, es decir, el aseguramiento, tanto del derecho a la revolución del pueblo, como del derecho a la resistencia de los ciudadanos. [...] Es decir, la juridicación de la soberanía popular comporta, inexcusablemente, el establecimiento de unas reglas sobre la formación de la voluntad soberana, pero no sobre el contenido de esa voluntad, porque el pueblo tiene que conservar la libertad de decidir, jurídicamente, su propio destino. [...] sólo cuando se juridifica el poder constituyente se cumple la pretensión que da sentido al Estado constitucional, que no es otra que enlazar, y no disociar, Democracia y Estado de Derecho.", M. ARagón ReYes, Constitución y Democracia, Madrid, 1989, págs. 34 y 36.

27 En palabras de G. ZaGReBeLSKY, «Para usar una imagen, el derecho constitucional es un conjunto de materiales de construcción pero la construcción en concreto no es la obra de la Constitución en cuanto tal sino de una política constitucional que se aplica a las combinaciones posibles de esos materiales. Las sociedades pluralistas actuales [...], es decir, las sociedades dotadas, en su conjunto, de un cierto relativismo, asignan a la Constitución la misión de realizar la condición de posibilidad de la vida en común, no la misión de realizar directamente un proyecto predeterminado de vida en común", en Il diritto mite, Einaudi, Turín, 1992, págs. 8 y 9. 
cas que se consideran relevantes en dicha comunidad: las económicas, las sociales, las ideológicas y, esto es importante, también las culturales ${ }^{28}$.

Ahora bien, esa retórica carecería de valor si no se concretase en la propia organización estatal, si esa diversidad reconocida no se proyectase en "peculiaridad constitucional" respecto de las normas constitucionales del pasado. Esta perspectiva adquiere relevancia, además, respecto de la organización territorial del poder en Estados que se caracterizan por la diversidad étnica, cultural o lingüística de las diferentes comunidades que se asientan en su territorio. En el ámbito del constitucionalismo anglosajón se han aportado soluciones interesantes en relación con los grupos indígenas (Canadá, Sudáfrica, Nueva Zelanda).

Y, a nuestro parecer, esa diversidad étnica, cultural o lingüística es la que dota de un carácter especial a la descentralización política propia de algunos países europeos. En efecto, en el ámbito de países como el Reino Unido, Bélgica o España, el reparto territorial del poder no puede entenderse simplemente como un instrumento técnico para lograr una organización estatal más eficaz y democrática; en estos Estados el federalismo es fundamentalmente un mecanismo de integración y de reconocimiento de la diversidad a partir de la unidad (que no de la homogeneidad). Los sistemas federales, en definitiva, necesitan reinventarse en la actualidad en estos países, en atención a sus especificidades; y eso puede conducir, sin duda, a la aceptación de asimetrías entre los distintos territorios del Estado (Escocia, Reino Unido), a diferencias competenciales (hechos diferenciales, España), o a organizaciones institucionales peculiares (Bélgica) ${ }^{29}$.

Después de todo lo dicho, cuando el Derecho constitucional ha llegado a un grado de evolución en el que los derechos de los ciudadanos se han situado en el centro del sistema; en el que el poder estatal se ha mitigado y se ha repartido y organizado a través de distintas instancias de poder, de frenos y contrapesos, que dificultan enormemente su uso abusivo; en el que el pluralismo, a través de sus múltiples manifestaciones, no es un mal a silenciar sino un

28 Esa es la impronta que caracteriza al Derecho constitucional de nuestros días, y así se muestra en las constituciones que se definen en la unidad a partir de la diversidad, como se explicita, por ejemplo, en el Proyecto de Constitución para Europa (art. I-8), o en la Constitución de la República de Sudáfrica (Preámbulo): «Nosotros, el pueblo de Sudáfrica..., considerando que Sudáfrica pertenece a todos los que viven en ella, unidos en nuestra diversidad".

29 Igualdad básica de todos los ciudadanos del Estado y pluralismo territorial son los dos principios-eje de estas formas de descentralización territorial. Como señala J. J. SOLOZÁBAL EchavARRÍA, "La visión constitutivamente plural de la Nación española, integrada por nacionalidades y regiones, implica ciertamente reconocer un relieve político a la variedad territorial. Desde este punto de vista la Constitución permite en concreto la realización de la vocación política de la nacionalidad, que dispone..., de una adecuada organización para asegurar y desarrollar su propia identidad, si bien este pluralismo territorial ni pone en cuestión la esencial unidad del espacio político común, objeto además de la lealtad política prevalente, ni abre el camino a la autodeterminación, o decisión soberana sobre la propia forma política, como desenlace irreversible de la conciencia política de la nacionalidad.", "El Estado autonómico como Estado nacional", ahora en Las bases constitucionales del Estado autonómico, McGrawHill, Madrid, 1998, pág. 103. 
bien a proteger por el Estado; en esta situación, cabe preguntarse si aún quedan tareas pendientes para el Derecho constitucional o, por el contrario, se ha creado una constitutio ex machina que funciona razonablemente bien y que sólo precisa de su vigilancia, de su control, y de su adaptación técnica ante nuevas realidades.

Parece fuera de discusión que el Derecho constitucional en particular (y el Derecho en general) ha alcanzado una extraordinaria precisión técnica, avalada por una multiplicidad de prescripciones normativas deducidas de la Constitución, de interpretaciones a las mismas, de combinaciones entre esas proposiciones lógicas, que permiten resolver y canalizar la amplia variedad de controversias que se suscitan en las complejas sociedades de nuestros días. Los asuntos relacionados con la bioética (eutanasia, uso de embriones), con las nuevas convenciones sociales (matrimonios entre personas del mismo sexo, multiculturalismo), con las modernas relaciones conflictivas entre estados (guerra preventiva contra el terrorismo), con la economía globalizada -u oligopolizada- (desregulación del tráfico ecónomico privado), etc., pueden abordarse a través del complejo jurídico formado por la Constitución normativa y la exuberante (por excesiva) legislación que ha crecido a su amparo.

Pero esta virtualidad "técnica" no es suficiente y puede resultar, incluso, contraproducente, porque "Las Leyes, y entre ellas la Constitución, pueden mucho pero no todo. Éstas forman una especie de gran construcción, pero no más sólida que un castillo de naipes, siempre que su fundamento se sitúe en ellas mismas: es decir, en último término, en el poder... El reto del constitucionalismo está en su totalidad aquí: en la capacidad de la Constitución, planteada como lex, de convertirse en ius; ..., en la capacidad de salir del área del poder y de las frías palabras de un texto escrito para dejarse atraer a la esfera vital de las convicciones y de las ideas queridas, sin las cuales no se puede vivir y a las que se adhiere con calor ${ }^{30}$.

En definitiva, si en el Estado constitucional la Constitución ha sido identificada como la "Biblia política" de la que "raramente una familia carece", "cada miembro del gobierno tiene una copia", y que se utiliza para encontrar solución "sobre cualquier principio legal" (T. Paine, Los derechos del hombre, 1792), pudiera ocurrir que, al haber sido la Constitución ensalzada y alejada de las convicciones profundas de los ciudadanos, a través de una liturgia y de un lenguaje (los jurídicos) que el común de los mortales no entiende, se vaya perdiendo el consenso social sobre el texto (constitucional) y sus preservadores (la clase política y la jurídica), como lo perdió la Iglesia Católica, precisamente, en el momento de la reforma.

Esta realidad puede relacionarse, en nuestra opinión, con el alto índice de abstención que se ha dado en el referéndum sobre el Tratado de la Constitución para Europa, o también, en una dimensión cuasiconstitucional, en los recientes referendos de ratificación de las reformas de los Estatutos de Autonomía de

30 G. Zagrebelsky, "La Ley, el Derecho y la Constitución", en Revista Española de Derecho Constitucional, $\mathrm{n}^{\circ} 72,2004$, págs. 22 y 23. 
Cataluña y de Andalucía. Una Constitución europea y unos Estatutos de contenido inabarcable y difícilmente aprehensible para los profanos (y también, incluso, para los no profanos), que no despiertan entre los ciudadanos un sentimiento de identificación y de adhesión como el que despertó en su momento la Constitución de 1978.

La legibilidad y la corporeidad de la Constitución y del Derecho constitucional es, por tanto, un reto que se ha de seguir sosteniendo en estos tiempos de ilegibilidad y virtualidad de la realidad. Además, esta tarea ha de hacerse compatible con la apertura del texto constitucional para poder asumir esa realidad mudable. Puede decirse que, en las coordenadas políticas, económicas y sociales de nuestros días, la Constitución es, permanentemente, un texto normativo in fieri, (re)haciéndose de manera constante para dar respuesta adecuada a cada nuevo problema. Eso es lo que cabe exigir a las constituciones democráticas actuales y para ello es de gran utilidad la jurisprudencia constitucional, como "instrumento" para llevar a cabo la actualización ordinaria de las normas constitucionales, al determinar las alternativas que permite el texto de la Norma fundamental ${ }^{31}$.

Pero hay otra actualización que no puede lograrse a través de dicha jurisprudencia y que hace imprescindible la reforma constitucional. En la práctica, es esta perspectiva la que se está comunizando cada vez más en el ámbito europeo y la que está quitando dramatismo y trascendencia fundadora a las reformas constitucionales, principalmente como consecuencia del horizonte europeo y de la necesidad de facilitar una integración cada vez más intensa, allanando ese camino a través de nuevos peldaños europeístas en los textos constitucionales. Esta visión de la Constitución como un "organismo vivo" (in fieri) al que no le son contraproducentes, por definición, las reformas, no es sin embargo la que ha prevalecido en nuestro país. Pero, quizás, debe ser tiempo ya para que las fuerzas políticas y la ciudadanía muestren su madurez para abordar reformas importantes de la Constitución, procurando, eso sí, que se mantenga la recognoscibilidad de la Norma fundamental.

Esta virtualidad del "aperturismo" constitucional es de gran trascendencia en el ámbito interno y supranacional de cada Estado, pero a día de hoy tiene una proyección esencial en el ámbito internacional o de la globalización. No cabe duda de que ha sido en ese espacio donde el constitucionalismo democrático muestra y ha mostrado sus limitaciones más evidentes. A este respecto, basta con echar un vistazo al desastre que han supuesto los procesos descolonizadores, con la creación de estructuras estatales que no se sostienen, lo que se vienen denominando como "estados fallidos" (failing states) o "estados

31 "Parece evidente que, como señala Hesse, "realización" de la Constitución e "interpretación" de ésta no son términos sinónimos, aunque toda interpretación implique "actualización" de la Constitución, [...] El juez constitucional crea normas constitucionales que, por serlo, no pueden ser modificadas ni desconocidas por el legislador. Naturalmente no las crea ex nibilo, sino como derivación de un "derecho más alto", cuyo sentido sólo él puede realizar", F. RuBio LLORENTE. "Problemas de la interpretación constitucional en la jurisprudencia del Tribunal Constitucional español", ahora en La forma del poder, CEC, Madrid, 1997, págs. 584, 587 y 588. 
débiles", incapaces de crear las condiciones mínimas de seguridad y de evitar las matanzas étnicas, la guerra civil, la anarquía o el caos. No admitir que esa es, en buena medida, la otra cara de la moneda de nuestra democracia y de nuestros estados del bienestar hará, a la postre, un flaco favor al constitucionalismo.

Sobre esta cuestión es muy interesante la reflexión realizada por la England and Wales High Court en su decisión de 14 de diciembre de 2004, dictada en un proceso planteado por los familiares de seis ciudadanos iraquíes muertos en Irak en el momento en que el Reino Unido era una potencia ocupante. Los demandantes solicitaban a la Alta Corte que se pronunciase acerca de la aplicación a estos supuestos de la CEDH y de la Human Rights Act del Parlamento británico (1998), y también, y como consecuencia, que se pronunciase acerca de la competencia de los órganos judiciales británicos para aplicar dichas normas (fundamentalmente, los arts. 2 y 3 del Convenio) a las actuaciones del ejército británico en Irak. Frente a las alegaciones del Gobierno británico, según las cuales «hay territorios en el mundo, como Irak, para los cuales no fue prevista la Convención y que no están preparados para la misma", la Alta Corte responde que "Nadie sabe a quién se entregará el testigo o los testigos de la raza humana (de la evolución humana). La Convención no fue creada a causa de la humanidad de Europa, sino a causa de sus fracasos".

Y tampoco parece convincente postular que ha llegado el fin de la historia (Fukuyama) y que eso tiene su manifestación en los forzados (y solamente formales o insuficientemente materiales) procesos democráticos llevados a cabo, por ejemplo, en Afganistán o en Irak. Por más que se quiera, no son realidades comparables a la Alemania o al Japón de la segunda posguerra mundial. En cierto sentido, la idea de la existencia de "democracias iliberales" de las que provendrían, en realidad, los principales peligros para el mundo actual $(<<\mathrm{La}$ democracia sin liberalismo constitucional no es simplemente inadecuada, sino peligrosa, trayendo consigo la erosión de la libertad, el abuso de poder, las divisiones étnicas e, incluso, la guerra $>>^{32}$ ), es un argumento que puede volverse en contra de quienes pueden ser sus principales valedores (neoconservadurismo en los Estados Unidos), porque igual que deslegitima a las "democracias iliberales" hostiles al mundo occidental, erradica de base todo sustento legitimador de las fórmulas "constitucionales y democráticas" instauradas por la fuerza con el beneplácito de las democracias liberales.

Por esta razón, quizás, haya que ser más modestos acerca de lo que el Derecho constitucional puede conseguir y acerca de los problemas y realidades que puede ordenar en nuestros días; su horizonte debe ser más limitado para que sea eficaz. Posiblemente sea éste el tipo de recorrido, menos ambicioso pero más realista, que permita dotar de alguna virtualidad efectiva, en algún momento histórico, a las predicciones de J-A-N. de Caritat, Marqués de Condorcet sobre "Los progresos futuros del espíritu humano": 
$<<$ Todas las naciones deben acercarse algún día al estado de civilización donde han llegado los pueblos más ilustrados, más libres, más exentos de prejuicios, como los franceses o los angloamericanos? ¿Esta inmensa distancia que separa a esos pueblos de la servidumbre de las naciones sometidas a reyes, de la barbarie de las poblaciones africanas, de la ignorancia de los salvajes, debe desvanecerse poco a poco? [...] Entonces los europeos, limitándose a un comercio libre, suficientemente ilustrados acerca de sus propios derechos como para no hacer caso de los de los otros pueblos, respetarán [su] independencia, que han violado hasta ahora con tanta audacia. Sus establecimientos, en lugar de llenarse de protegidos de los gobernantes que, por el favor de una plaza o de un privilegio, corren a amasar tesoros por el bandidaje y la perfidia, para regresar después a Europa a comprar honores y títulos, se poblarán de hombres industriosos, que irán a buscar en esos climas felices el desahogo que les rehuye en su patria. La libertad los retendrá allí; la ambición dejará de llamarles; y esos condados de bandidos se convertirán en colonias de ciudadanos que retomarán, en África y en Asia, los principios y el ejemplo de la libertad, las luces y la razón de Europa... > 33 .

\begin{abstract}
This article deals with the essential characteristics that defines the constitutional state from the liberal revolutions onwards. The evolution of constitutionalism compels to maintain a certain relativism about the tasks to be entrusted to the constitutional texts in the ordering of coexistence. Just in this way it would be possible to distinguish between genuine constitutional states and states which can not stand on as such, and just in this way it would be possible to manage a concept of constitution less transcendental and more appropriate to the reality, more flexible to adapt to the rapid evolution of the present political communities.
\end{abstract}

33 Esquisse d'un tableau des progrès de l'esprit humain, ed. Prior-Belaval, París, 1970, págs. 203 y ss. (hay traducción al castellano, con una introducción previa, de A. TORRES DEL MORAL, Bosquejo de un cuadro bistórico de los progresos del espíritu humano, CEPC, Madrid, 2004). 